\title{
Increment of seismicity of the building area depending on soil conditions
}

\author{
Rasulov Khayat ${ }^{\text {i) }}$ and Rasulov Rustam ${ }^{\text {ii) }}$ \\ i) Professor, Department of Civil Engineering, Tashkent Architectural Building Institute, Tashkent, Uzbekistan \\ ii) Senior scientific worker researcher, Tashkent Architectural Building Institute, Tashkent, Uzbekistan
}

\begin{abstract}
This report is devoted to one of topical questions of a seismic building - to specification of seismicity of a territory depending on concrete soil conditions of the building area. It is noticed that the method of seismo-districts widely applied now possesses suffer from grave shortcomings, in particular, with reference to concrete soil conditions. It in great degrees concerns a choice of the reference soil corresponding to seismicity of territory on a card of seismic zoning. For definition increment mark of seismicity on others soils concerning the reference the indicator of acoustic rigidity (product of density of a soil for speed of distribution of seismic waves) and position of level of subsoil waters is used. At such approach to the question decision all soils (except rock) give an identical increment mark, irrespective of their properties and conditions. As have shown results of numerous experimental researches, question decisions above-mentioned by practically in all cases yield the results far differing from observed phenomenon in the nature. It is based on that the indicator of acoustic rigidity not in all soils depends on their humidity (sand, gravel, rubble, rigid clay and rock). Humidity of a soil can be a matter only for clay soils in plastic conditions. Besides in the given approach to the question decision are not considered physic-mechanical and stability indicators of a concrete soil, in each special case providing its seismic stability. The proposed method offered by the author is deprived above mention lacks.
\end{abstract}

Keywords: increment forced, threshold acceleration, a method of the seismo-steady basis, durability, coefficient of seismic stability

\section{INTRODUCTION}

Now specification of seismicity of an area of building is made on the basis of cards of the seismic micro-division into districts, allowing to estimate intensity of the phenomenon in mark. Usually such estimation is accompanied by instructions of the maximum seismic acceleration $\left(a_{s}\right)$, defining marks and necessary for an establishment of a value of seismic factor $\left(k_{c}\right)$, necessary for calculation of seismic inertial loading which is necessary for considering at designing of constructions.

All existing methods of seismic micro-division into districts have the general beginning, at division into districts of any territory. It is necessary to allocate from the analysis of geological engineering and hydro geological materials of the studied area so-called "a standard soil" which concerns mark on a card of seismic division into districts. Further for increment definition marks on others soil concerning standard, the indicator of acoustic rigidity (product of density of a soil for speed of distribution in it of seismic waves) and the level of subsurface waters is used. Thus, all soils (except rock and semi-rock) are defined an identical increment marks, irrespective of physic-mechanical and strengths their properties.

As shows the analysis of buildings and the constructions which have had at Earthquakes failure to some extent, the estimation of seismo-stability of the bases on an indicator of acoustic rigidity is not always justified and can be used only at preservation by a soil of the elastic condition at fluctuation.

However, as results of research, the condition of elasticity water sated friable weak soils at concussion quite often appears broken. Besides statement marks territories on dependence on position of subsurface waters as it follows from the recommendation on seismic micro-division is not always justified. So, for example, many researches of authors with all persuasiveness have shown results, that soil deformation at various fluctuations depends on mainly strength and deformation characteristics of a soil and a thickness of a fluctuating layer. At the same time not in all soils the above-named characteristics depend on their humidity.

\section{METHOD}

As an example it is possible to note sandy, large granular (gravel, rubble, etc.), rigid clay, rock, etc. 
versions soils in durability and which deformations humidity of any role does not play. At the same time, clay soils only in plastic conditions appear strongly depending on their condition of humidity. Humidifying semi-rock soils (plaster, stone salt, etc.) also can lower their seismo-durability. This circumstance has allowed authors to carry out researches on revealing of the true factors rendering influences on an increment seismic marks various soils at their fluctuation. In this course, mainly, it was represented expedient to investigate a role strength indicators of a soil and a thickness of a fluctuating soil in seismo-durability of rocks. Noted positions have served as the reason for working out of more perfect methods of an estimation of an increment marks, allowing to express the phenomena already in a quantitative kind with the account in each special case strength characteristics and a concrete thickness composing soils.

So, for definition of an increment seismic marks area D. D. Barkan's started with settlement resistance of soil depending from strength of characteristics soils of an area, that, certainly, is the perfect approach to the decision of question (D.D Barkan (1975)). However the given approach to the question decision also is not deprived lacks as in it the thickness of a fluctuating soil is not considered. Such gap it is corrected by $\mathrm{H}$. Rasulovby (1984) working out "the seismo-steady basis", it agree which estimation seismic marks a building site and its increment. It is established on values of threshold acceleration at peculiar to given soil conditions. The concept of threshold acceleration is entered for the first time into a science by D.D.Barkan (1975) and further "critical acceleration" is widely used by N.N.Maslov (1959) under the name.

Threshold acceleration is understood as such acceleration of concussion below which the considered soil keeps the static condition, above its value of structure of a soil starts to be broken (Rasulovby (1984)). Threshold acceleration $a_{t}$ is determined using formula from H. Z. Rasulov (1984) as follow.

$$
a_{t}=\frac{2 \pi g\left(\sigma t g \varphi_{w}+c_{v}\right)}{\gamma_{w} \cdot T \cdot v_{s}}
$$

where $\sigma$ is normal pressure from weight of constructions and weight of the soil which is above considered horizon; $\varphi_{w}$ is an internal friction angle of soil at humidity $w ; c_{v}$ is the general coupling of a soil at humidity $w ; \gamma_{w}$ is wet density of a natural ground; $T$ is the fluctuation period; $v_{s}$ is velocity of seismic waves. According to this dependence seismic stability of structure of any soils is defined, first of all, by their static durability expressed to resistibility to shift $\left(\varphi_{w}, c_{v}\right)$, and also their thickness natural location $\left(T, v_{s}\right)$.

This position has received the acknowledgement on numerous experiences on various on structure and a condition soils in different dynamic modes (fig. $1-4$ ).

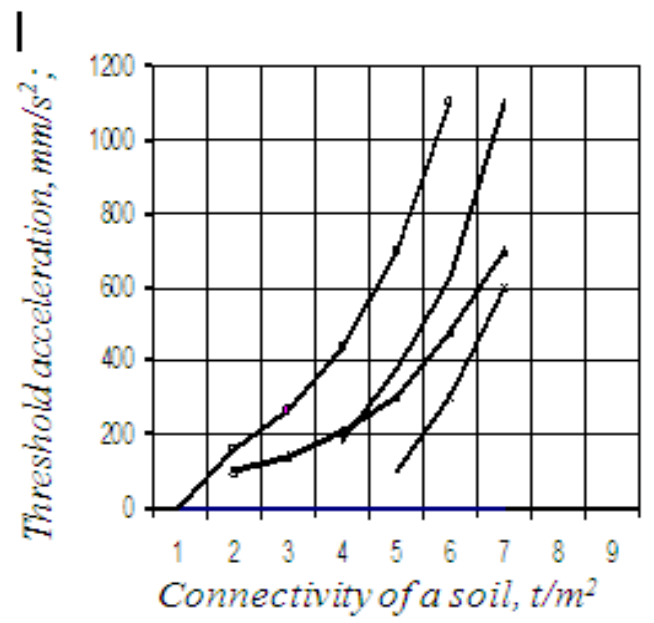

Fig. 1 Dependency of threshold acceleration of connectivity of a soil.

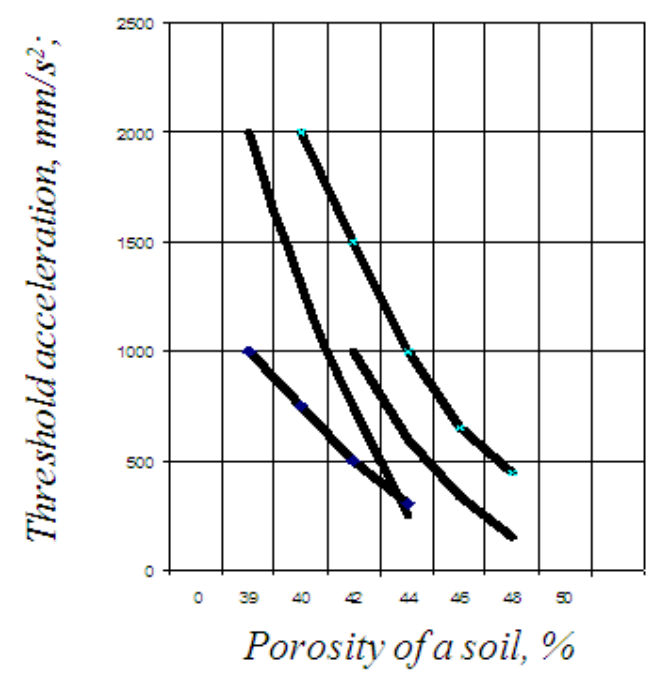

Fig. 2. Relationships between threshold acceleration and porosity of soil.

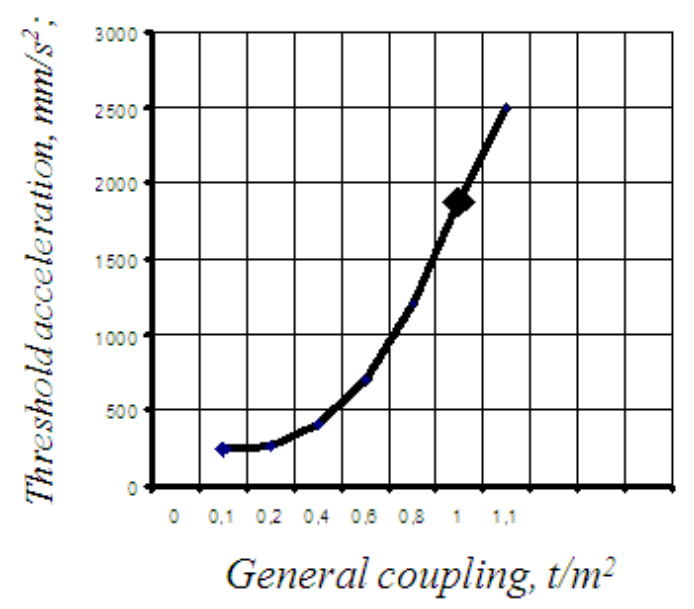

Fig. 3. Dependence of threshold acceleration on the general coupling of a loessial soil, $a=2500-2800 \mathrm{~mm} / \mathrm{s}^{2}$ 


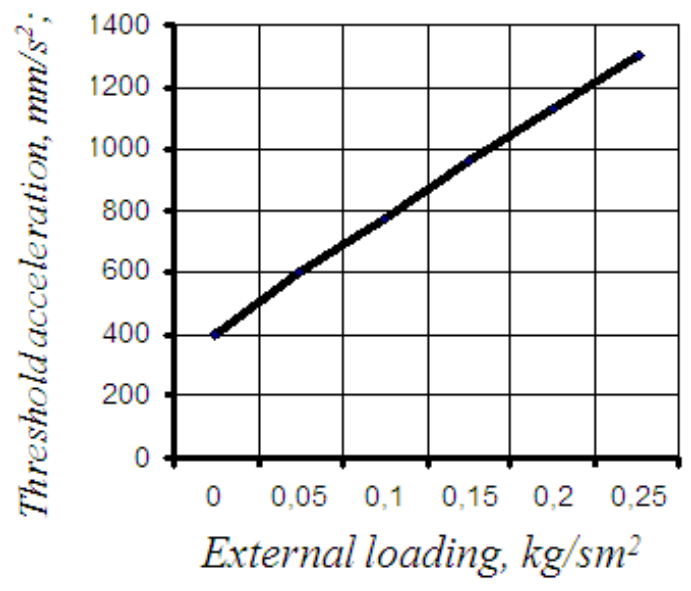

Fig. 4. Dependence of threshold acceleration on external loading at a thickness of soil $\mathrm{H}=200 \mathrm{~cm}$.

As is known, soils in each special case are defined by those or other parameters defining their durability. So, for example, durability of rocky soils is caused by the rigid structural coupling giving to them known hardness (Fig. 5).

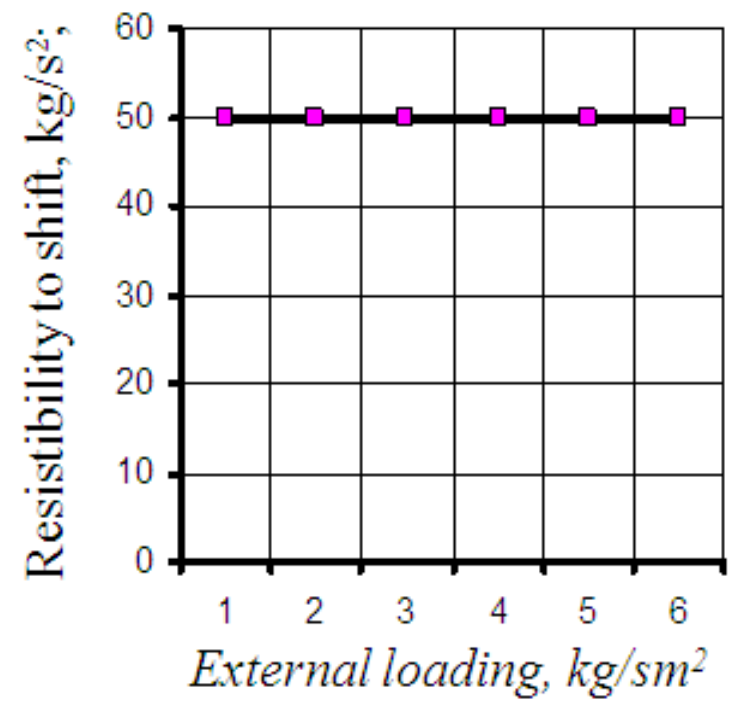

Fig. 5. Dependence of resistibility to shift of a rocky soil from loading.

Durability cohesion less soils in the most friable condition see is defined by a corner of an internal friction and normal pressure (Fig. 6, the bottom line). With increase in their density some forces of coupling (Fig. 6, the top lines) start to be shown. At the same time, durability coherent soils in certain degree depends and on size of the connectivity having connectedness the nature (Fig. 7). It once again testifies that durability of every one of versions soils is defined by various indicators depending on a kind, conditions location, and also a natural condition of their density-humidity. At the same time, this circumstance also testifies to various

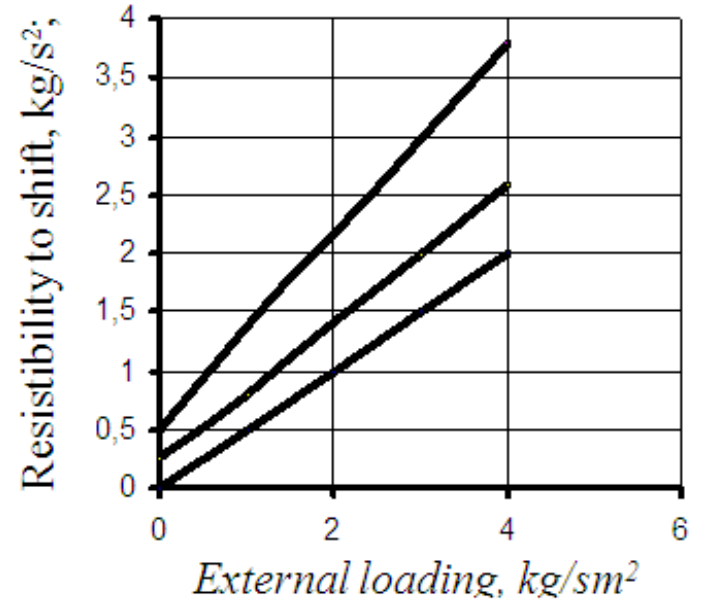

Fig. 6. Dependence of resistibility to shift of a sandy soil from loading.

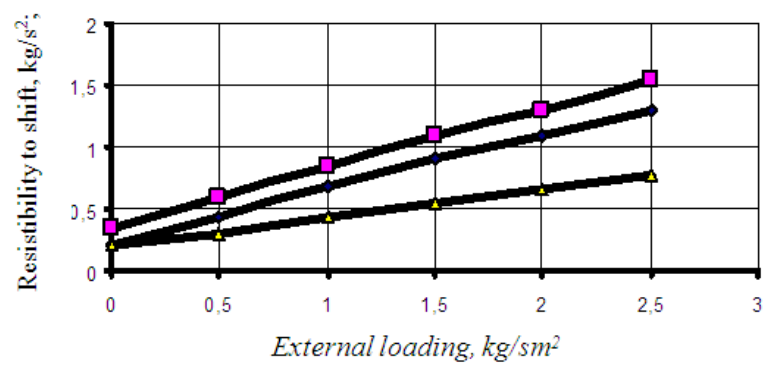

Fig. 7. Resistibility to shift of a clay soil at various humidity the sample on the schedule moisture content is killed from below upwards.

dynamic stability soils in the bases of constructions. With itis necessary to be considered at an estimation of an increment seismic mark a concrete building site.

According to a method of "the seismo-steady basis" the increment mark a building area is defined on values of factor of seismic stability $k_{s t}$ as following equation.

$$
k_{s t}=\frac{a_{t}}{a_{s}}
$$

Where $a_{s}$ is the maximum seismic acceleration corresponding mark of area on a card of seismic division into districts. A conformity condition mark a concrete area with mark, established for data area (on a reference ground) is $k_{s t}=1.0$.

Finally the value of the seismic stability $k_{s t}$ calculated using equation (2) is used in calculations as the correction factor considering concrete soil conditions. This account in the simplest form can be carried out using following equation.

$$
k_{s}^{c}=\frac{k_{s}}{k_{s t}}
$$

Where $k_{s}^{c}$ is settlement value of factor of seismicity; $k_{s}$ is the factor of seismicity of area and it is equalled for $7-0.025$; for $8-0.05$; for $9-0.1$. 


\section{SUMMARY}

Advantage of a method of "the seismo-steady basis" is its simplicity and comparative accuracy. Work by definition of parameters of resistibility to shift and capacity of thickness can be executed engineering geological expeditions and the building organizations without additional expenses. One of advantages of the proposed method is reliability of received results. A basis to it is the account of changes strength of soil characteristics in concrete conditions of Earthquake.

\section{REFERENCES}

1) Maslov N.N. (1959): Condition of stability of the water sated sand, Publishing house "Energy", Moscow, Russia, 328 p.

2) Barkan D.D., et al. (1975) Influence of properties soils the bases at calculation of constructions on seismic influence, Materials of III - Conference on dynamics of the bases and underground constructions, Publishing house "Fan", Tashkent, Uzbekistan, 48-51.

3) Rasulov H.Z. (1984) Seismic stability of the soil bases. Publishing house "Uzbekistan", 191 p. 